\title{
Bioinspired cavity regulation on superhydrophobic spheres for drag reduction in an aqueous medium
}

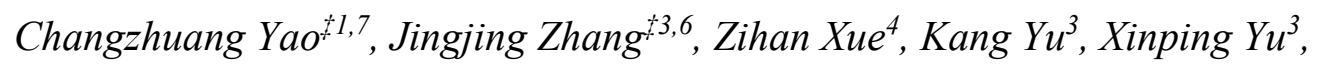

Xiaoxiao Yang ${ }^{8}$, Qiulin Qu ${ }^{5}$, Wenbiao Gan ${ }^{4}$, Jingming Wang ${ }^{2 *}$, and Lei Jiang ${ }^{1,7}$

1 CAS Key Laboratory of Bio-inspired Materials and Interface Sciences, Technical Institute of Physics and Chemistry, Chinese Academy of Sciences, Beijing 100190, P.R. China

2 School of Materials Science and Engineering, Beijing University of Chemical Technology, Beijing 100029, P. R. China

E-mail: wangjm@buaa.edu.cn

3 Key Laboratory of Bio-Inspired Smart Interfacial Science and Technology of Ministry of Education, School of Chemistry, Beihang University, Beijing 100191, P. R. China

4 Key Laboratory of Advanced Technology of Intelligent Unmanned Flight System of Ministry of Industry and Information Technology, Beihang University, Beijing 100191, P. R. China

5 School of Aeronautic Science and Engineering, Beihang University, Beijing 100191, P. R. China

6 BAIC Motor Corporation. Ltd, Beijing 101300, P. R. China

7 Future Technology College, University of Chinese Academy of Sciences, Beijing 100190, P. R. China

8 Department of Energy and Power Engineering, Tsinghua University, Beijing 100084, P. R. China 
S1 Wettability of the copper plates and spheres with different microstructures and chemical components

The static contact angles (CAs) of water droplets on the copper plates and spheres with different microstructures and chemical components were compared, as shown in Figure S1. The copper plates and spheres were treated with the same chemical procedures. The CAs were measured by the CA analyzer (OCA 20, Data-physics, Germany). The volume of the water drop was $2 \mu \mathrm{L}$. The CAs on the copper plates and spheres with same microstructures and chemical components exhibited similar degrees. The modified sphere with micro-nano structures showed the CA of close to $0^{\circ}$, which was a bit smaller than that on the cooper plate $\left(4.2 \pm 4.0^{\circ}\right)$.
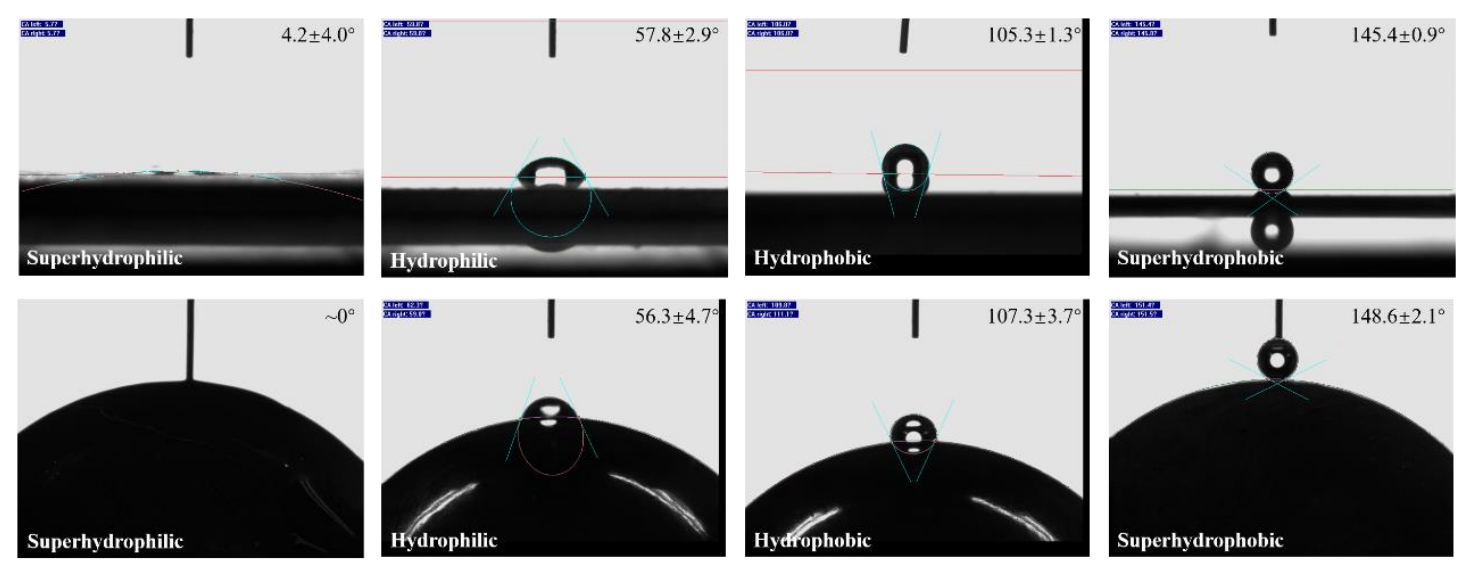

Figure S1 The static contact angles on the copper plates and spheres with different microstructures and chemical components.

To investigate the wattabilities of the copper plates and spheres with different microstructures and chemical components, we further measured the dynamic CAs on the copper plates (superhydrophilic, hydrophilic, hydrophobic, and superhydrophobic 
plates) and the copper spheres (hydrophilic, hydrophobic spheres), as shown in Figures S2 and S3, respectively. The initial volume of the water drop was $2 \mu \mathrm{L}$, and the injecting/re-injecting speed was $0.3 \mu \mathrm{L} / \mathrm{s}$. Superhydrophobic surfaces showed a large static CA and a small CA hysteresis.
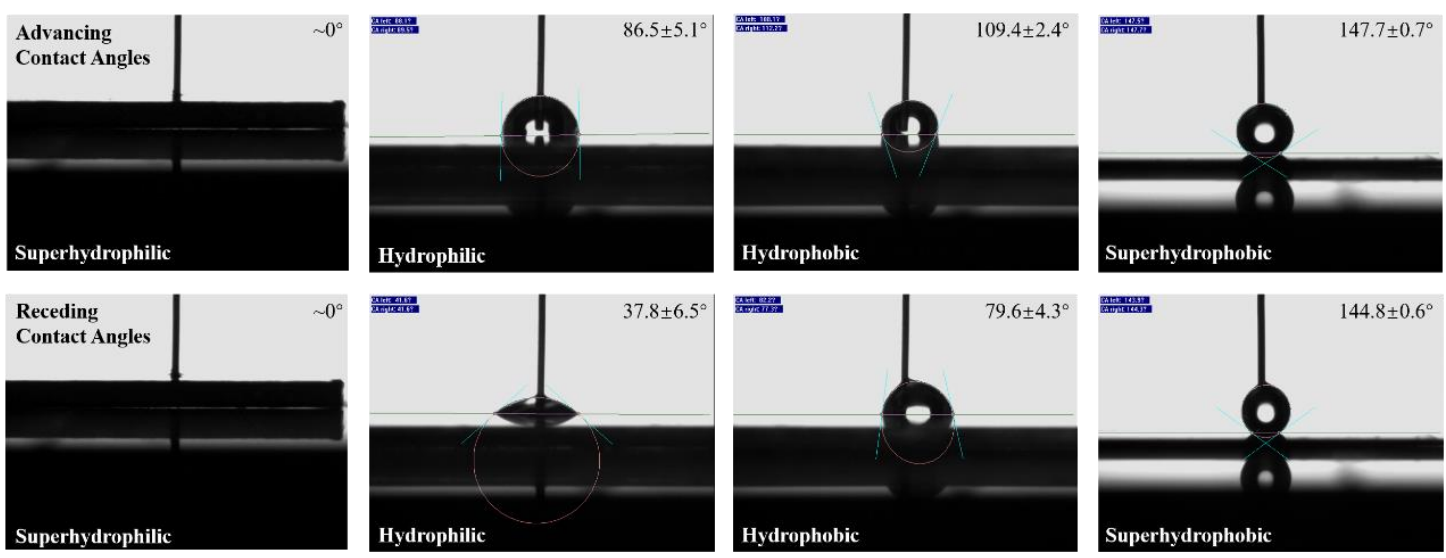

Figure S2 The advancing and receding CAs on the superhydrophilic, hydrophilic, hydrophobic, and superhydrophobic copper plates.
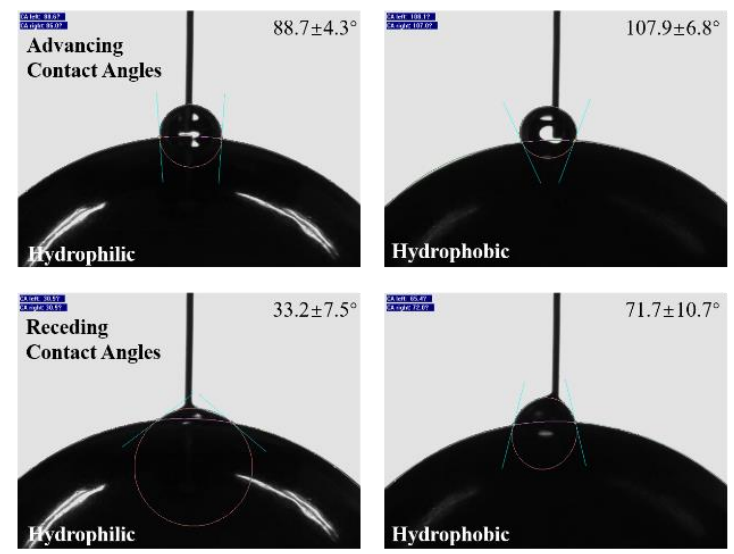

Figure S3 The advancing and receding CAs on the copper hydrophilic and hydrophobic spheres.

The stability of the air cushion on the superhydrophobic sphere was investigated. The stability experiment was performed in the PMMA square tube with the length of $15.0 \mathrm{~cm}$, width of $15.0 \mathrm{~cm}$, and height of $40.0 \mathrm{~cm}$. Deionized water was placed in the PMMA tube for at least 24 hours to remove the microbubbles. 
As shown in the Figure S4, a superhydrophobic sphere was immersed underwater at a depth of $20.0 \mathrm{~cm}$. The silver-mirror sheen phenomenon was observed on the surface of superhydrophobic sphere, indicating that the superhydrophobic sphere can retain the air cushion underwater in the Cassie state. After the immersion of 180 min underwater, there was still a gas layer trapped on the superhydrophobic surface. These results demonstrated that the fabricated superhydrophobic surface can maintain the Cassie state underwater for a longevity more than one hour. In addition, in the process of cavity formation (pinching off timescale $\sim 100 \mathrm{~ms}$ ), the superhydrophobic sphere can maintain the Cassie state and stabilize the gas-liquid interface.

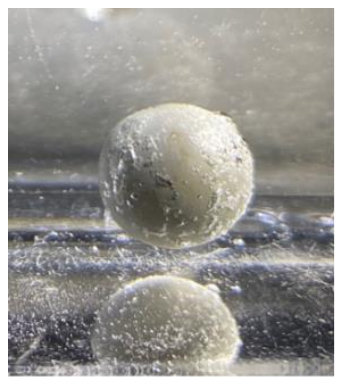

0 min

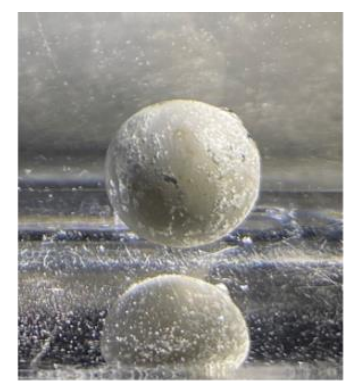

$60 \mathrm{~min}$

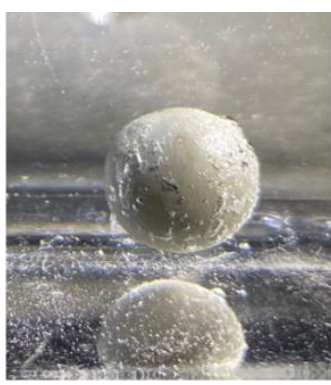

$120 \mathrm{~min}$

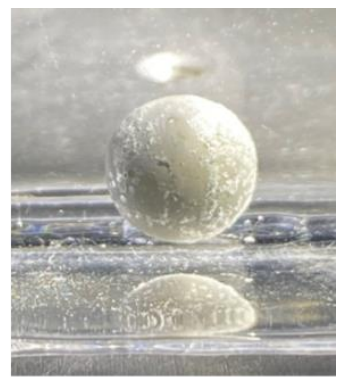

$180 \min$

Figure S4 The images of the immersed superhydrophobic sphere The spheres were immersed at depth of $20.0 \mathrm{~cm}$ at different time ( $0 \mathrm{~min}, 60 \mathrm{~min}, 120 \mathrm{~min}$, and $180 \mathrm{~min}$ ). The diameter of the sphere is $10 \mathrm{~mm}$.

S2 The influence of mechanical robustness of the fabricated texture on the cavity shape of superhydrophobic spheres

To investigate the mechanical robustness of the fabricated superhydrophobic texture, we performed the repeated water impacting experiments of one superhydrophobic sphere with tweezer holding. The water entry experiments were performed in a PMMA square tube with a length of $15.0 \mathrm{~cm}$, a width of $15.0 \mathrm{~cm}$, and a 
height of $40.0 \mathrm{~cm}$, which was full of water. After the superhydrophobic sphere reached and impacted the tube bottom, the superhydrophobic sphere was taken out from the PMMA tube with the tweezer, and immersed in the ethyl alcohol for $1 \mathrm{~min}$. Then the superhydrophobic sphere was taken out, and drying at $60^{\circ}$ for $5 \mathrm{~min}$. Then the superhydrophobic sphere was held by the tweezer again to perform the repeated water impacting experiment. The superhydrophobic sphere with diameter $10 \mathrm{~mm}$ was released from the same height $20 \mathrm{~cm}$ in the repeated experiment. The experimental results were shown in Figure S5.

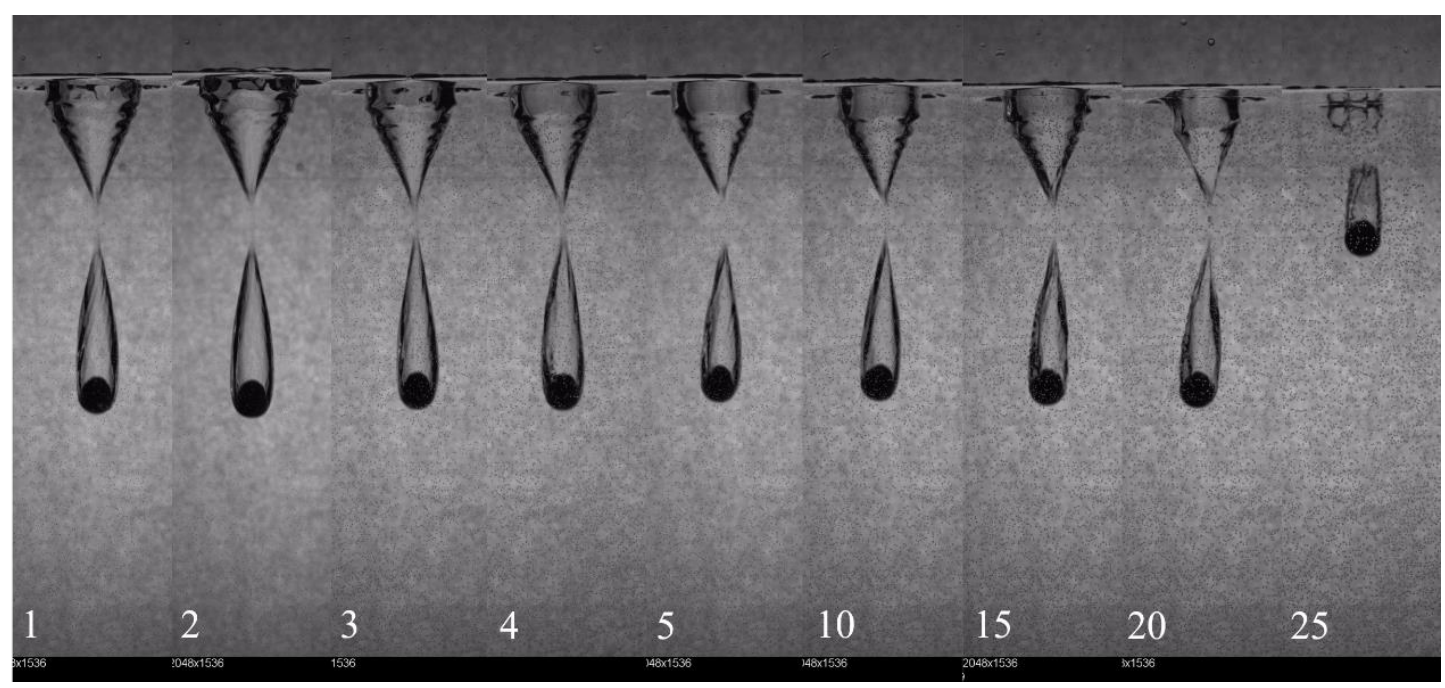

Figure S5 Selected snapshot showed the impacting processes of the superhydrophobic sphere with different times of repetition, 1, 2, 3, 4, 5, 10, 15, 20, and 25 times. The snapshots were taken just after the cavity pinching off.

When the superhydrophobic sphere impacted the water surface at the first time, the shape of the cavity was symmetrical. After the sphere impacting the tube bottom, the sphere was taken out from the tube and checked carefully. There was no obvious damage on the sphere surface. After the fifth repeated test, the shape of the cavity tended to be asymmetrical, and the entrained volume of the cavity gradually decreased. This is because the repeated impacting processes of the sphere onto the water surface 
and tube bottom, and the holding processes of tweezer caused damage of the surface texture. At the $25^{\text {th }}$ times of repeated tests, only small volume of cavity was trapped. In such cases, the surface texture had been greatly damaged.

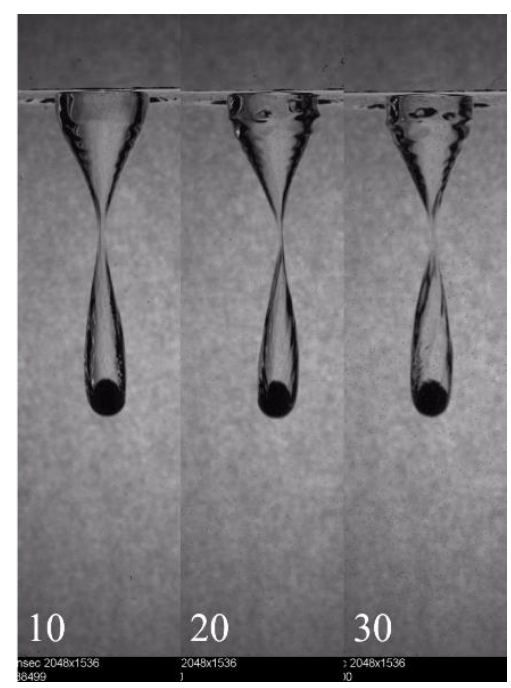

Figure S6 Selected snapshot showed the impacting processes of the superhydrophobic sphere with different dropping times onto the steel plate (10, 20, and 30 times). The snapshots were taken just after the cavity pinching off.

We further investigated in the impacting processes of the superhydrophobic sphere which was dropped on the solid floor. The superhydrophobic sphere hit onto a steel plate from the dropping height of $50.0 \mathrm{~cm}$ with different times. Then, the superhydrophobic sphere was held by the tweezer to perform the water impacting experiment with releasing height $20.0 \mathrm{~cm}$. The experiment results were shown in Figure S6. The dropping processes on the steel plate caused some damage to the surface texture, resulting in a little asymmetric shape of the cavity. However, there was still a large cavity trapped by the impacting sphere. These results demonstrate that the slight damage of texture had little influence on the shape of the cavity. 
S3 Influence of diameters and impacting velocities of the hydrophilic and hydrophobic spheres on the air-entrained cavity

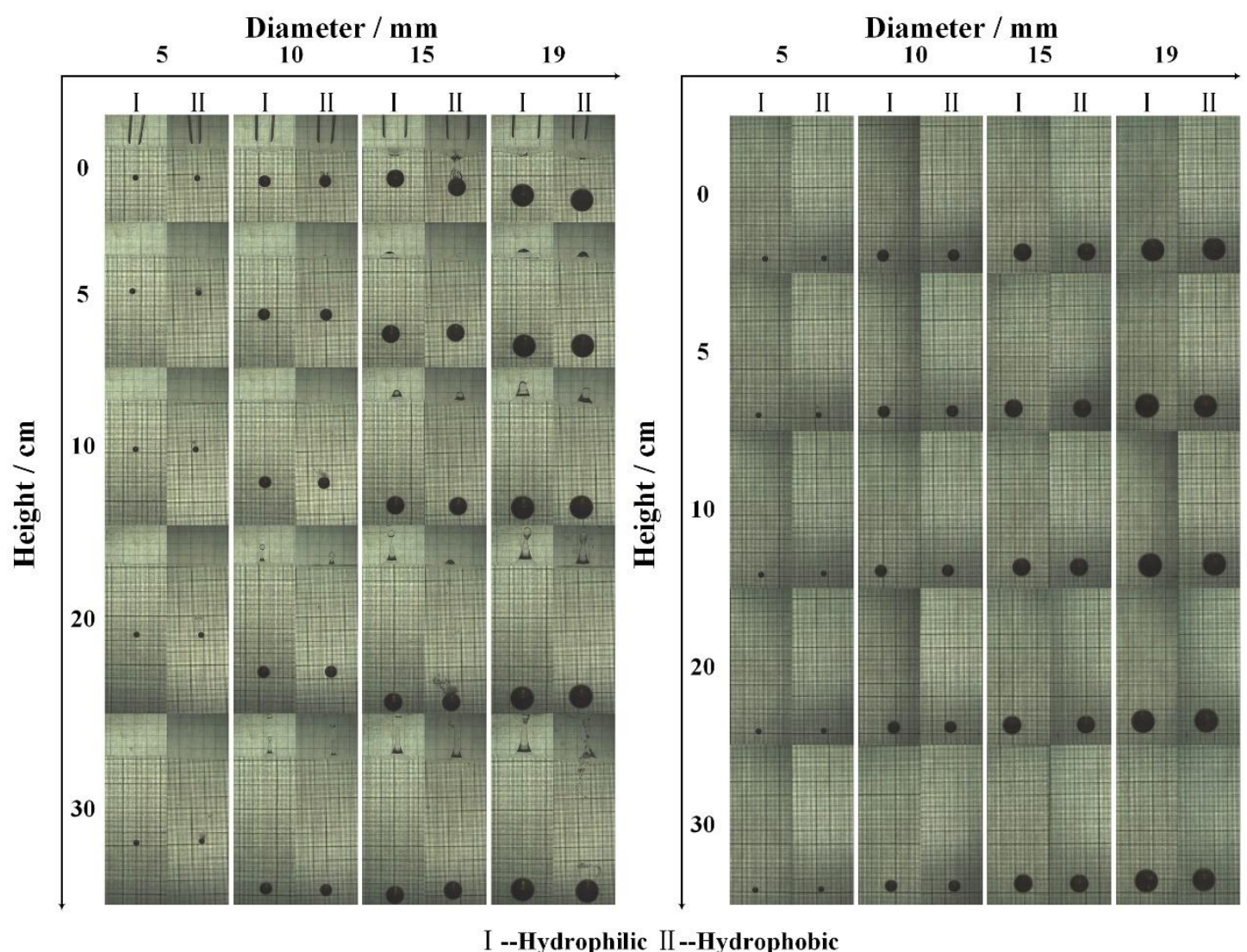

Figure S7 Selected snapshot showed the consequence of (a) water impacting and (b) underwater uniform motion of the hydrophilic and hydrophobic spheres with different spherical diameters of $5.0 \mathrm{~cm}, 10.0 \mathrm{~cm}, 15.0 \mathrm{~cm}$, and $19.0 \mathrm{~cm}$, and different releasing heights of $0 \mathrm{~cm}, 5.0 \mathrm{~cm}, 10.0 \mathrm{~cm}, 20.0 \mathrm{~cm}$, and $30.0 \mathrm{~cm}$. 
S4 Average velocities measured at different depths of the superhydrophobic and smooth hydrophilic spheres with different diameters
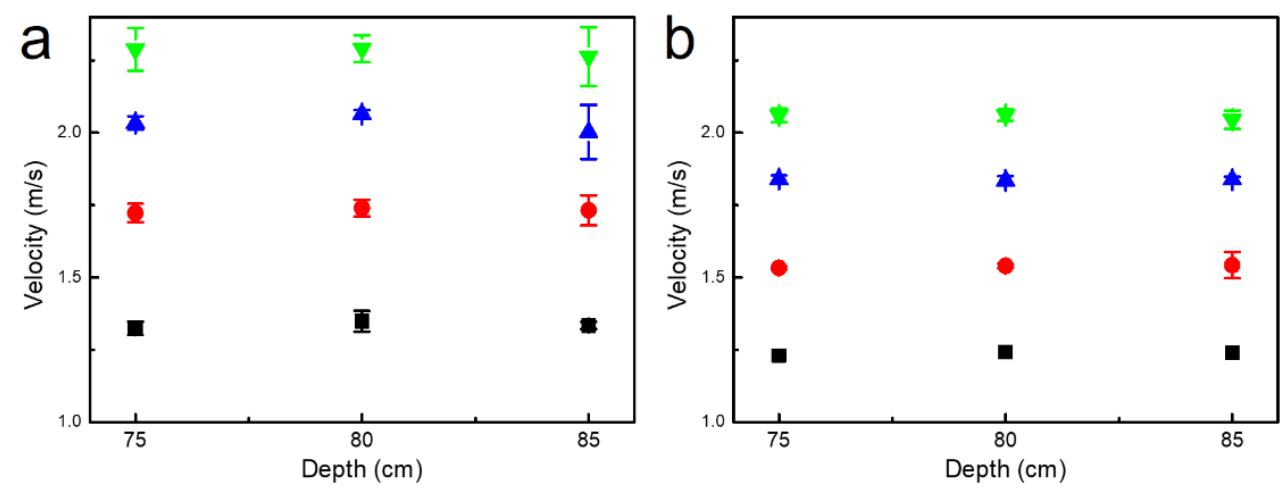

Figure S8 Average velocities measured at different depths $(75.0 \mathrm{~cm}, 80.0 \mathrm{~cm}$, and 85.0 $\mathrm{cm}$ ) of (a) the superhydrophobic and (b) smooth hydrophilic spheres with different diameters $5.0 \mathrm{~mm}$ (black square), $10.0 \mathrm{~mm}$ (red circular), $15.0 \mathrm{~mm}$ (blue up triangles), and $19.0 \mathrm{~mm}$ (green down triangles). The releasing heights of all the spheres were 30.0 $\mathrm{cm}$. 


\section{S5 The stability of the cavity on the superhydrophobic sphere}

To investigate the stability of the cavity on the superhydrophobic sphere, we compared the shapes of air-entrained cavities on superhydrophobic spheres with a diameter of $19.0 \mathrm{~mm}$ at different depth, including the depth regions of cavity pinching off, $70-90 \mathrm{~cm}$ and $130-150 \mathrm{~cm}$ underwater.
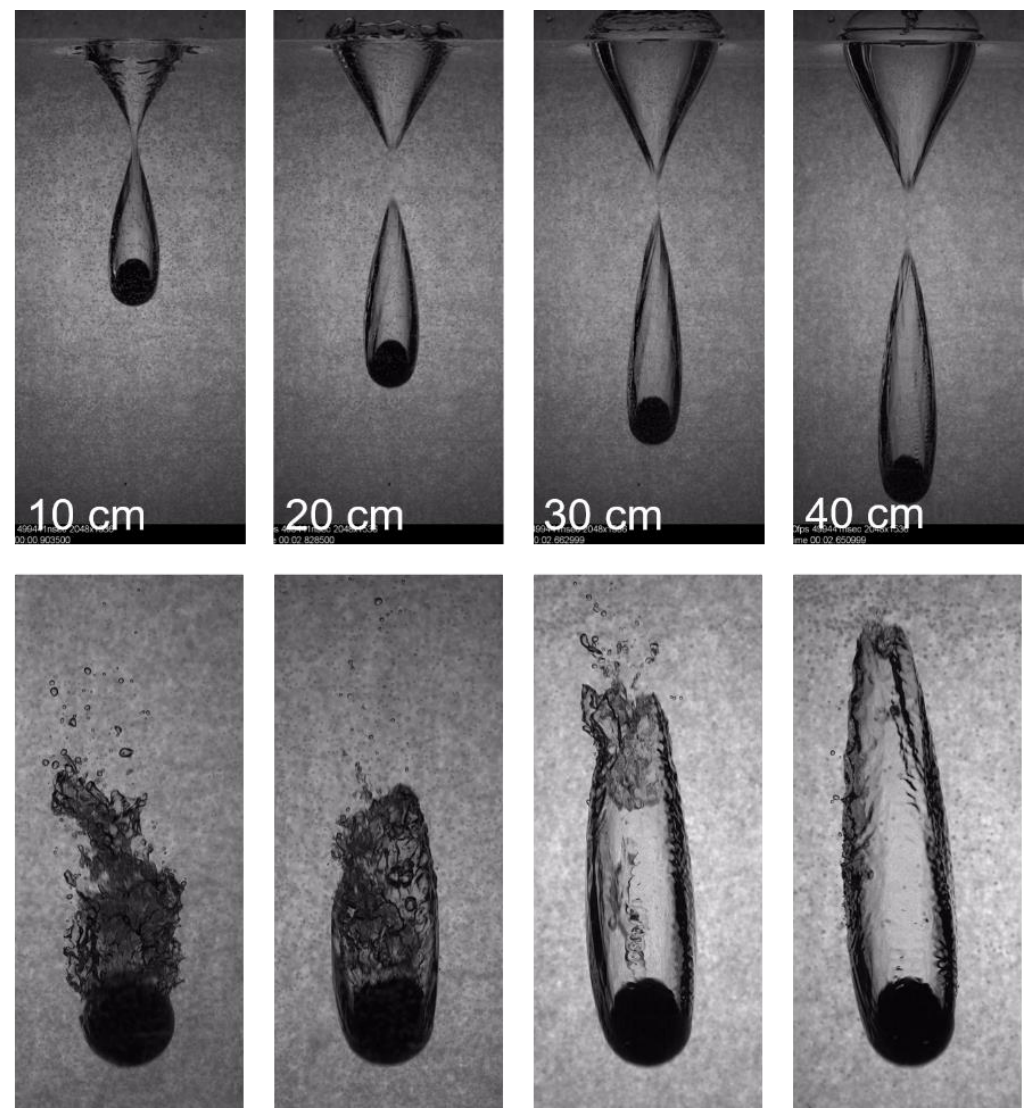

Figure S9 Selected snapshot showed the shapes of air-entrained cavities (a) after pinching off and (b) at the depth region of $70-90 \mathrm{~cm}$ uniform motion of the superhydrophobic spheres with different releasing height $(10 \mathrm{~cm}, 20 \mathrm{~cm}, 30 \mathrm{~cm}$, and 40 $\mathrm{cm})$.

After the middle part of the cavity pinched off, the front part of the cavity attached to the interface of the superhydrophobic spheres with different releasing height (10.0 $\mathrm{cm}, 20.0 \mathrm{~cm}, 30.0 \mathrm{~cm}$, and $40.0 \mathrm{~cm}$ ), showing perfect water-drop outline shapes (Figure 
S9a). The release higher height of the superhydrophobic sphere induced cavity with larger volume.
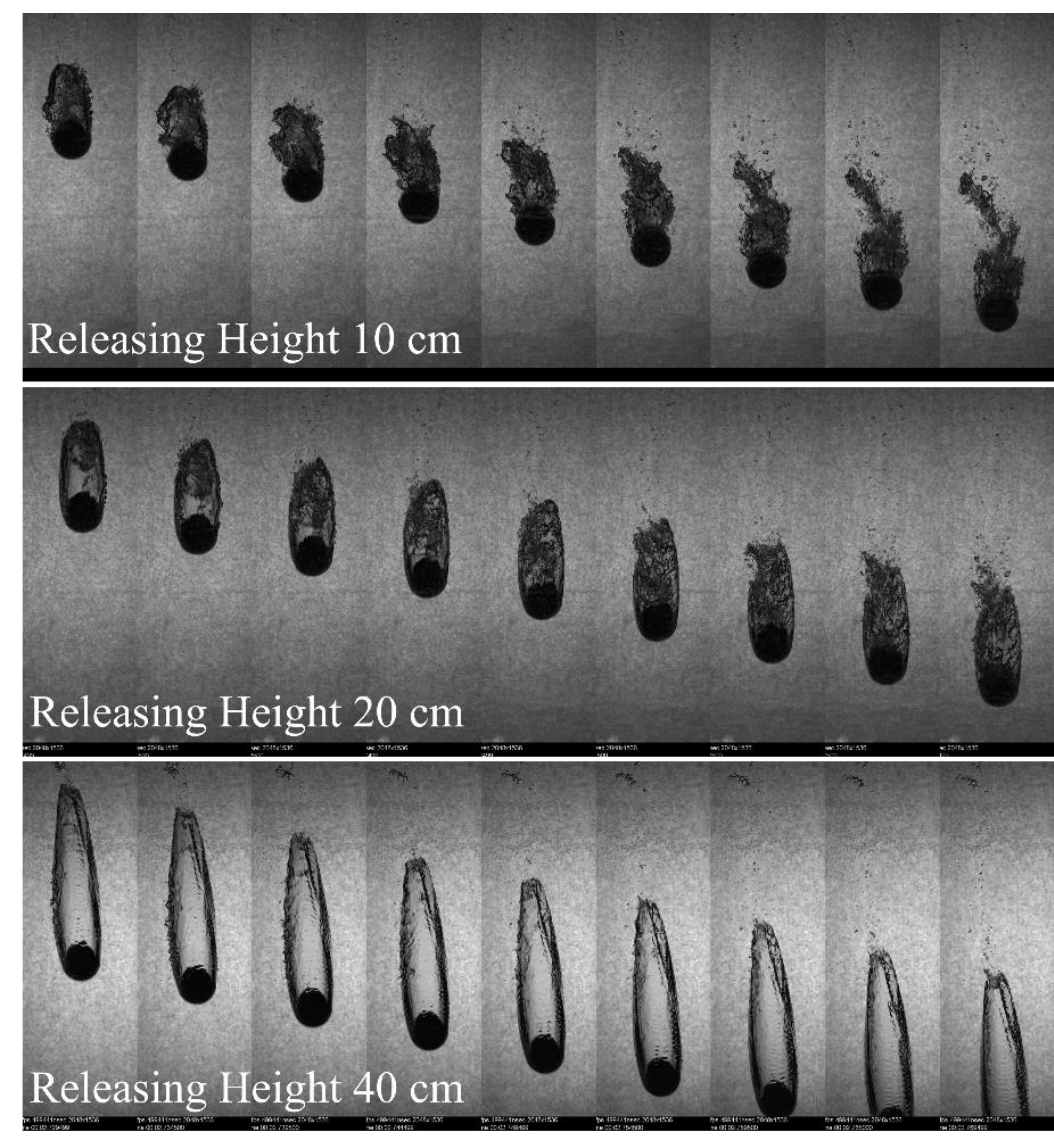

Figure S10 Successive snapshots of underwater uniform motion of the superhydrophobic spheres with different releasing height of $10 \mathrm{~cm}, 20 \mathrm{~cm}$, and $40 \mathrm{~cm}$, (i.e., different cavity volumes) at the depth region of $70-90 \mathrm{~cm}$. The time interval of the adjacent images is $5 \mathrm{~ms}$.

When the superhydrophobic spheres moved uniformly underwater at the depth region of 70-90 cm, the cavities' shapes changed in varying degrees, as shown in Figure S9b. With the increase of the cavity volume, the cavities' shapes became more streamlined, and the surface the cavities became smoother. The cavity seemed to be not 
very stable, and there were numerous released tiny bubbles, wrinkles and irregular waves on the cavity surfaces. To further investigate the instability of the cavity, the successive images of underwater uniform motion of the superhydrophobic spheres with different cavity volumes (i.e., different releasing height of $10 \mathrm{~cm}, 20 \mathrm{~cm}$, and $40 \mathrm{~cm}$ ) were shown in Figure S10.

In the case of the sphere with small volume (i.e., with releasing height $10.0 \mathrm{~cm}$ ), the cavity surface was very instable. Large amounts of bubbles were shed from the tail of the cavity. This is because flow separation was occurred behind the blunt tail of cavity, and the strong turbulence in the wake made the cavity surface instable. When the releasing height was increased to $20.0 \mathrm{~cm}$, the cavity volume increased, and their shape became more streamlined. There was still a large flow separation region behind the cavity, resulting in the wrinkles of cavity surface. When the releasing height reached $40.0 \mathrm{~cm}$, the cavity shape became streamlined with a weakened flow separation region, and the cavity became stable. Only small amounts of bubbles were shed from the tail. Thus, the cavity with a larger volume can optimized the cavity shape and flow field, and further suppressed the flow separation, which not only caused the drag increase but also the cavity instability.

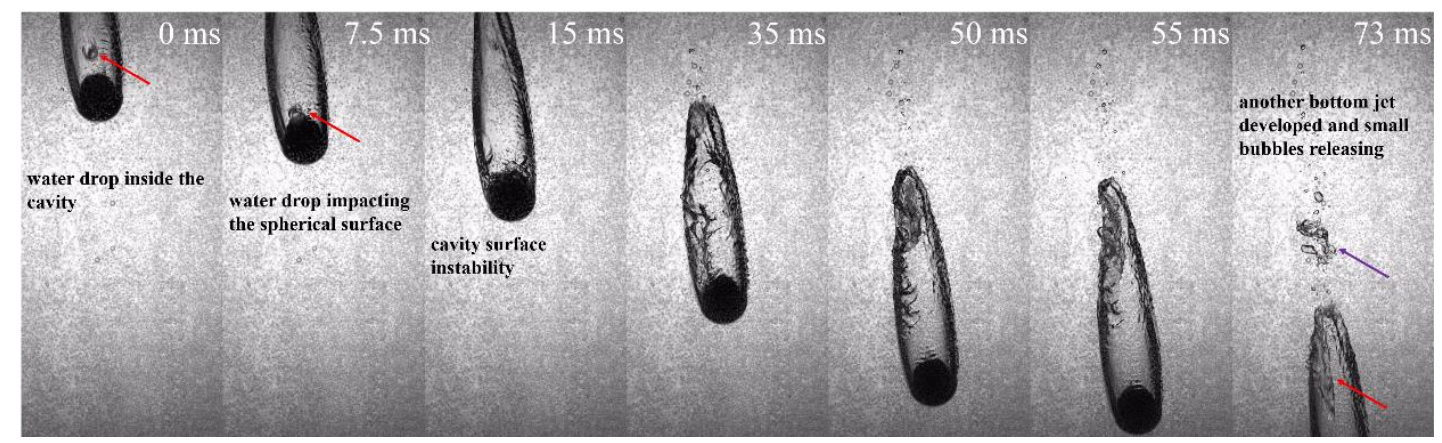

Figure S11 Successive snapshots of underwater uniform motion of the superhydrophobic spheres with releasing height of $40 \mathrm{~cm}$ at the depth region of 130$150 \mathrm{~cm}$. 
We further tracing the motion of the superhydrophobic spheres at the depth region 130-150 cm (Figure S11). The superhydrophobic sphere with diameter of $19.0 \mathrm{~mm}$ was released from $40.0 \mathrm{~cm}$ height above the water surface. As shown in the Figure S11, the cavity kept attaching to the spherical surface, showing a streamlined outline shape.

In this depth region, we observed another instability state of the underwater cavity. At the timepoint $0 \mathrm{~ms}$, there was a small water droplet inside the cavity (marked by the red arrow), accompanying with the falling of the sphere. At $7.5 \mathrm{~ms}$, the inside water droplet impacted the superhydrophobic sphere surface, resulting in the instable wrinkles near the bottom part of the cavity $(15 \mathrm{~ms})$. With the further falling of the sphere, the instable wrinkles were transferred upward to the tail of the cavity, resulting a small amount of bubble shedding from the tail of the cavity (73 ms). At the same time, the front part of the cavity recovered to stable state with a relatively smooth cavity surface. Moreover, at $73 \mathrm{~ms}$, we observed a downward jet (marked by the red arrow) was developed from the tail of cavity. Thus, we deduce that the small water observed at $0 \mathrm{~ms}$ was a consequence of the downward jet. The surface tension made the jet flow tended to be a water droplet when it approached the cavity surface.

The downward jet was induced by the increase of hydrostatic pressure of the surrounding water. Because the density of the inside air is much smaller than the surrounding water, the pressure inside the cavity can be considered as constant. With the falling motion of the superhydrophobic sphere, the hydrostatic pressure of the surrounding water was gradually increased. In addition, at the tail of the cavity, the Laplace pressure induced by the surface tension kept the cavity surface stable and intact. If the hydrostatic pressure was larger than the sum of the pressure inside the cavity and the Laplace pressure induced by the surface tension, there would be a downward jet developed inside the cavity. 
Therefore, there were two factor caused instability of the underwater cavity. One factor is flow separation behind the sphere. The cavity with a large volume and a perfect streamlined body shape can diminish this instability factor. The other is the increasing hydrostatic pressure of the surrounding water. The instability can be transferred upward to the tail of the cavity, resulting in the decrease of cavity volume. Cavity can recover to stable state because of the air-entrained capability of the superhydrophobic sphere.

\section{S6 The parallel motion of two $10.0 \mathrm{~mm}$ spheres with different wettabilities}

To avoid the wall effect and the mutual interference of four spheres, we can only investigate the parallel motion of two $10.0 \mathrm{~mm}$ spheres with different wettabilities (i.e., hydrophilic and hydrophobic spheres, hydrophilic and superhydrophobic spheres, hydrophobic and superhydrophobic spheres, and superhydrophilic and superhydrophobic spheres) limited by the tank size $(150.0 \mathrm{~mm} \times 150.0 \mathrm{~mm} \times$ $400.0 / 2000.0 \mathrm{~mm})$. To eliminate rotation of the spheres and make them to impact the water surface as simultaneously as possible, we used steel spheres with diameters of $10.0 \mathrm{~mm}$ to replace cooper ones. We used the electromagnet to control the release processes of the spheres. Thin copper films with thickness of about $20 \mu \mathrm{m}$ were electroplated on the steel spheres. The same procedures were used to make steel spheres achieve different wettabilities. The impact and motion processes of two parallel spheres was illustrated in Figures S12 to S15. The releasing height of all the spheres were 17.0 $\mathrm{cm}$, corresponding to the initial impacting velocities of $2.425 \mathrm{~m} / \mathrm{s}$. Because of the response sensitivity and accuracy, it is difficult to make two spheres release at same milliseconds. Thus, the initial heights of two spheres are slightly different.

As shown in Figure S13 after the hydrophilic and hydrophobic spheres passed through the free water surface, no air-entrained cavity was observed on the impacting spheres. The relative position of the two spheres changed little. In contrast, when 
superhydrophobic spheres impacted the water surface, large hourglass-shaped airentrained cavities formed (Figures S14 to S15). According to the relative position of the spheres with (i.e., superhydrophobic spheres) and without air-entrained cavities (hydrophilic, hydrophobic and superhydrophilic spheres), the spheres with airentrained cavities (i.e., superhydrophobic spheres) achieved higher velocities than those without air-entrained cavities.

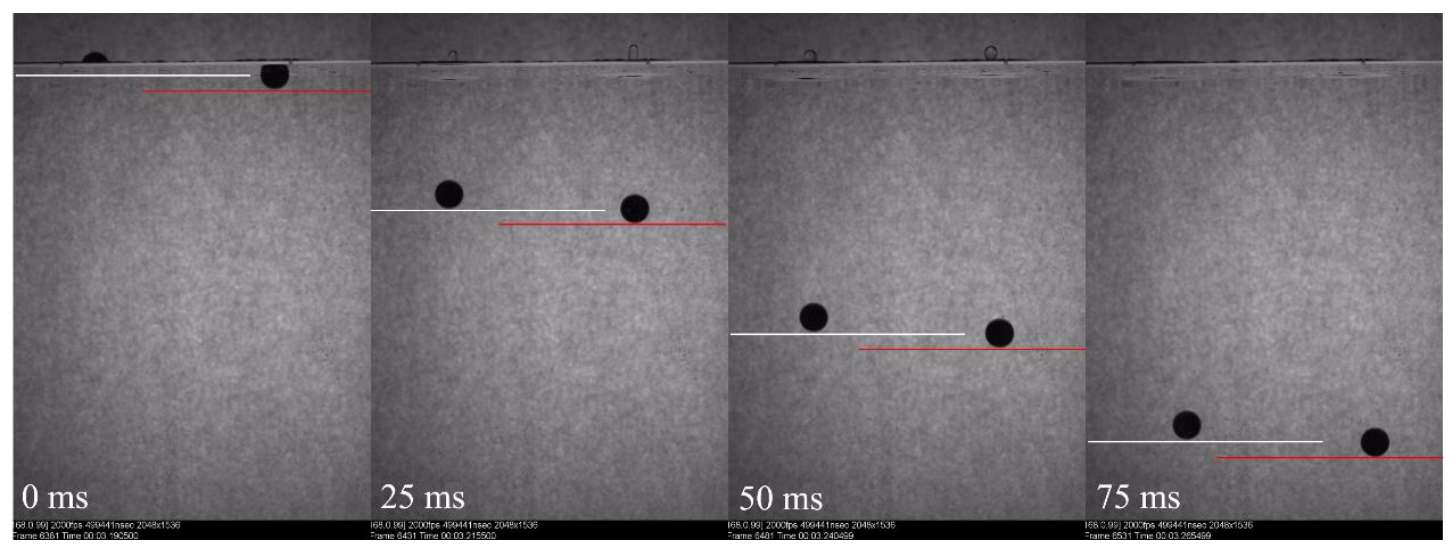

Figure S12 Successive snapshots of the water impacting of hydrophilic (left) and hydrophobic (right) spheres (with diameters of $10.0 \mathrm{~mm}$ ).

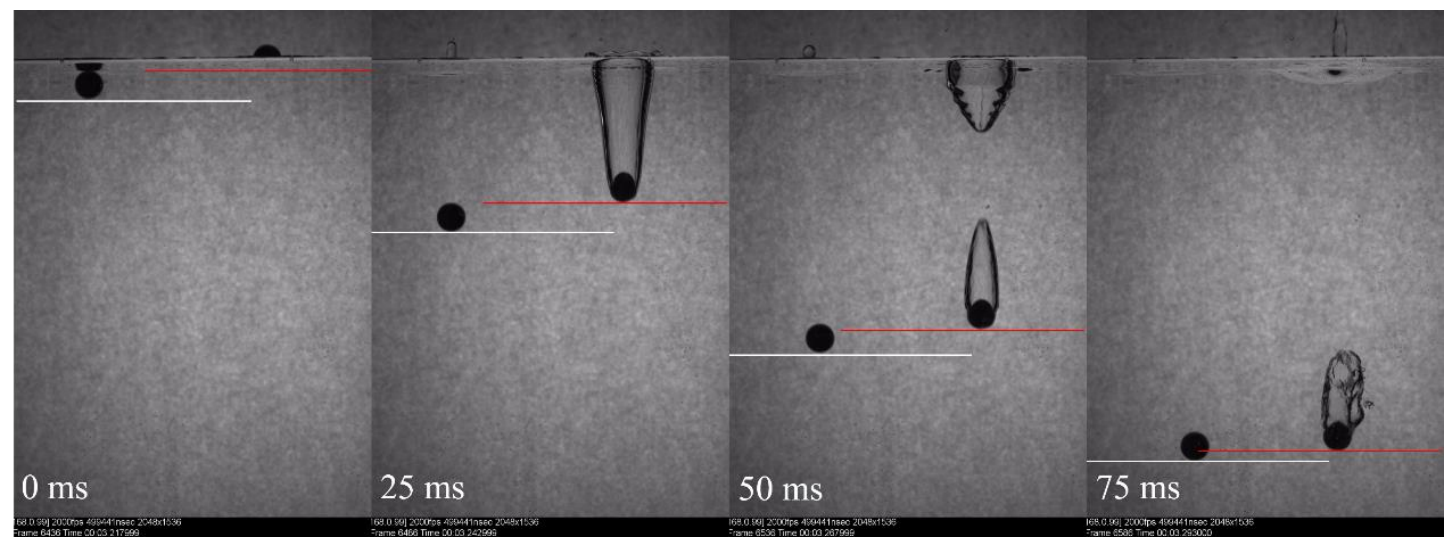

Figure S13 Successive snapshots of the water impacting of hydrophilic (left) and superhydrophobic (right) spheres 1 (with diameters of $10.0 \mathrm{~mm}$ ). 


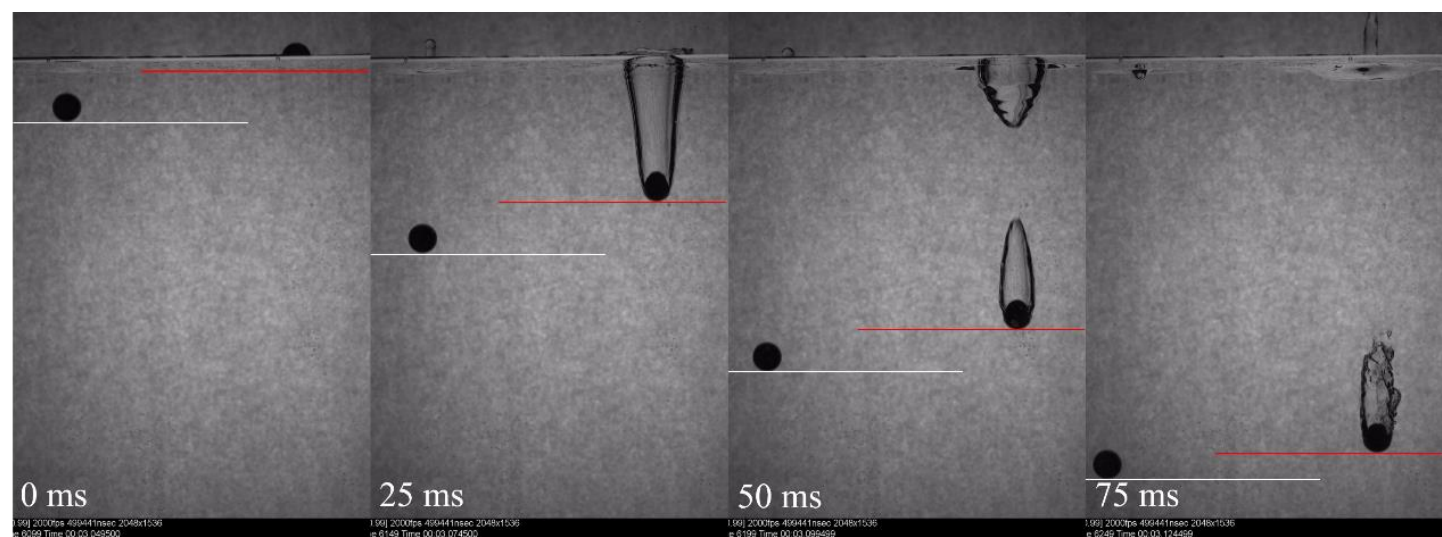

Figure S14 Successive snapshots of the water impacting of the hydrophobic (left) and superhydrophobic (right) spheres (with diameters of $10.0 \mathrm{~mm}$ ).

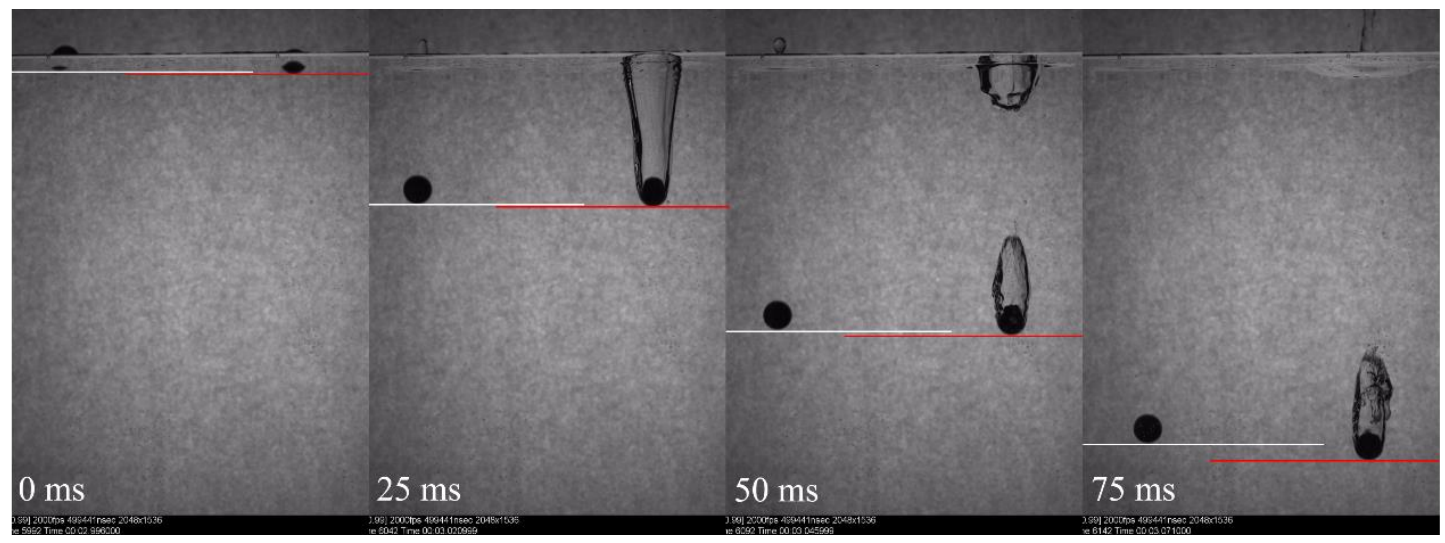

Figure S15 Successive snapshots of the water impacting of superhydrophilic (left) and superhydrophobic (right) spheres (with diameters of $10.0 \mathrm{~mm}$ ).

\section{S7 The wall effect for the dropping experiment/terminal velocity}

The water entry experiments were performed in a PMMA square tube with a length of $15.0 \mathrm{~cm}$, a width of $15.0 \mathrm{~cm}$, and a height of $40.0 \mathrm{~cm}$. The underwater movement experiment was performed in a PMMA square tube with a length of $15.0 \mathrm{~cm}$, a width of $15.0 \mathrm{~cm}$, and a height of $100.0 \mathrm{~cm}$. The spheres were released to the center of the 
PMMA square tubes above the water surface. As for the sphere used in our experiment with largest diameter of $19.0 \mathrm{~mm}$, the distance from the spherical center to the wall of the square tube was about $6.5 \mathrm{~cm}$, which is more than 3 times of the spherical diameter. According to the numerical result of Chen. and coworkers ${ }^{1}$, the reflection of the impactinduced gravity-capillary waves from tube wall had a little effect on the water entry process of the spheres. In our experiment, the Re region of falling spheres were $10^{3}$ to $10^{4}$ when they reached the terminal velocities. In this Re region, the error is only $\pm 1 \%$ as for the falling sphere. ${ }^{2}$ Thus, the wall effect had a little influence on the water entry and terminal velocity determination experiment.

\section{S8 Calculation of the volume of the underwater cavity}

The volume of the underwater cavity was found to increase with the releasing height. With the increase of the releasing height, the cavity shape gradually developed and tended to be more streamlined. According to the snapshots air-entrained cavities in the depth region of 70-90 cm with different releasing height $(10 \mathrm{~cm}, 20 \mathrm{~cm}, 30 \mathrm{~cm}$, and $40 \mathrm{~cm}$, Figure S9, there are two kind of cavity shapes. They are fully developed cavities generated at large release height (for example, $40.0 \mathrm{~cm}$ for the $19.0 \mathrm{~mm}$ spheres) and non-fully developed cavity (the rear part of the cavity was not intact) generated at small release height (for example, $20.0 \mathrm{~cm}$ for the $19.0 \mathrm{~mm}$ spheres). The $\mathrm{V}_{\mathrm{c}}$ was calculated by fitting the image of underwater cavity with algebraic curves, then integrating the fitting curves to obtain $\mathrm{V}_{\mathrm{c}}{ }^{3}$ 


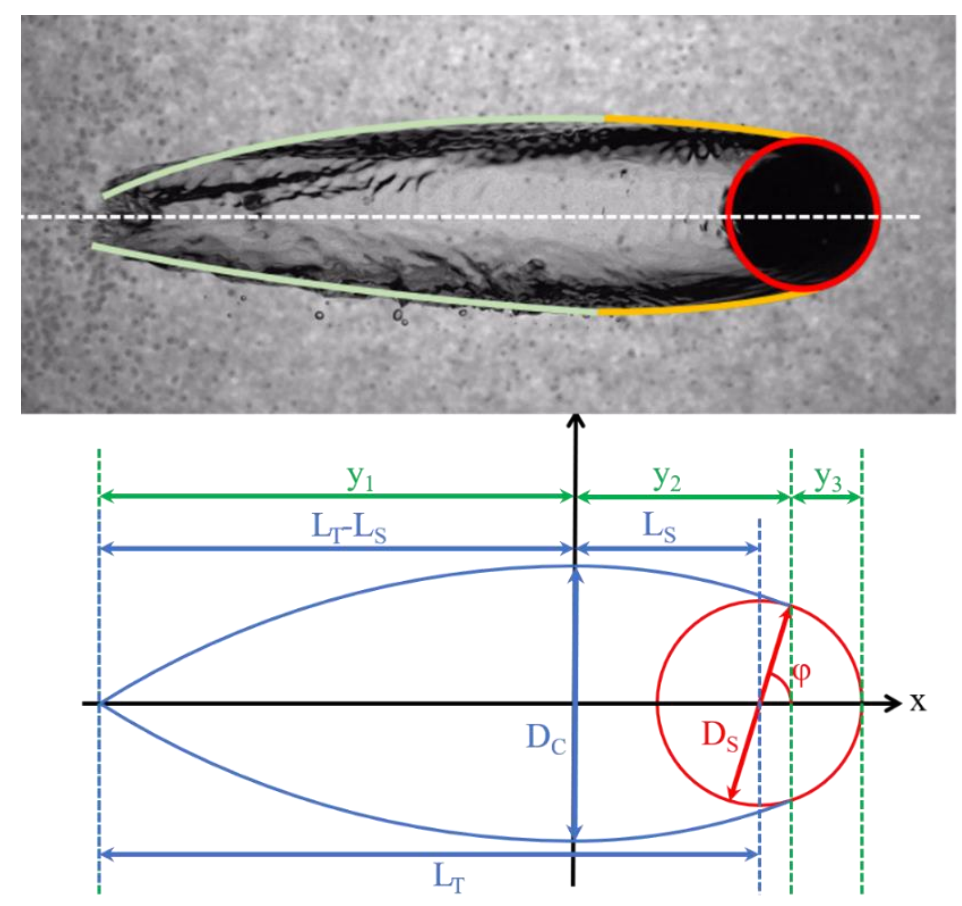

Figure S16 Illustration of curve fitting method of fully developed cavities sustained on a superhydrophobic sphere.

As for the fully developed cavity with the waterdrop shape, the algebraic curves contained three pieces, as illustrated in Figure S16. The cross section of the sphere with cavity was placed in a 2D coordinate plane, and the latitude of the cavity with maximal diameter $\mathrm{D}_{\mathrm{C}}$ was selected as $\mathrm{y}$-axis. The section from the tail of the cavity to the $\mathrm{y}$-axis was fitted by the parabola $y_{1}=\left[1-\left(\frac{x}{a_{1}}\right)^{2}\right] b_{1}$. To simplify the calculation, the section from the $y$-axis to the latitude where cavity intersected with the sphere was fitted by another parabola, $y_{2}=\left[1-\left(\frac{x}{a_{2}}\right)^{2}\right] b_{2}$. Moreover, other characteristic length of the cavity was defined: $\mathrm{L}_{\mathrm{T}}$ is defined as the length from cavity tail to the spherical center; $\mathrm{L}_{\mathrm{S}}$ is defined as the length from the latitude of the cavity with maximal diameter to the spherical center; $\varphi$ is the angle from the point where cavity intersected with the sphere to the latitude of spherical center, $D_{S}$ is the diameter of the solid sphere. The total 
volume $\mathrm{V}_{\mathrm{c}}$ can be calculated by integration $\int \pi y^{2} d x$. The integration result is as follows.

$V_{c}=\frac{\pi D_{C}^{2}}{4}\left[\frac{8}{15}\left(L_{T}-L_{S}\right)+\left(L_{S}+\frac{D_{S} \cos \varphi}{2}\right) y_{0}\right]+\frac{\pi D_{S}^{2} \sin \varphi}{4}\left(\frac{3 D_{S}-D_{S} \sin \varphi}{6}\right)$

where $y_{0}=1-\frac{2}{3}\left(\frac{D_{R}-D_{S} \sin \varphi}{D_{R}}\right)+\frac{4}{5}\left(\frac{D_{R}-D_{S} \sin \varphi}{D_{R}}\right)^{2}$.

$\mathrm{L}_{\mathrm{T}}, \mathrm{L}_{\mathrm{S}}$ and $\varphi$ can be measured by the open access software. In this case, the calculated $\mathrm{V}_{\mathrm{C}}$ contained the volume of the solid sphere.
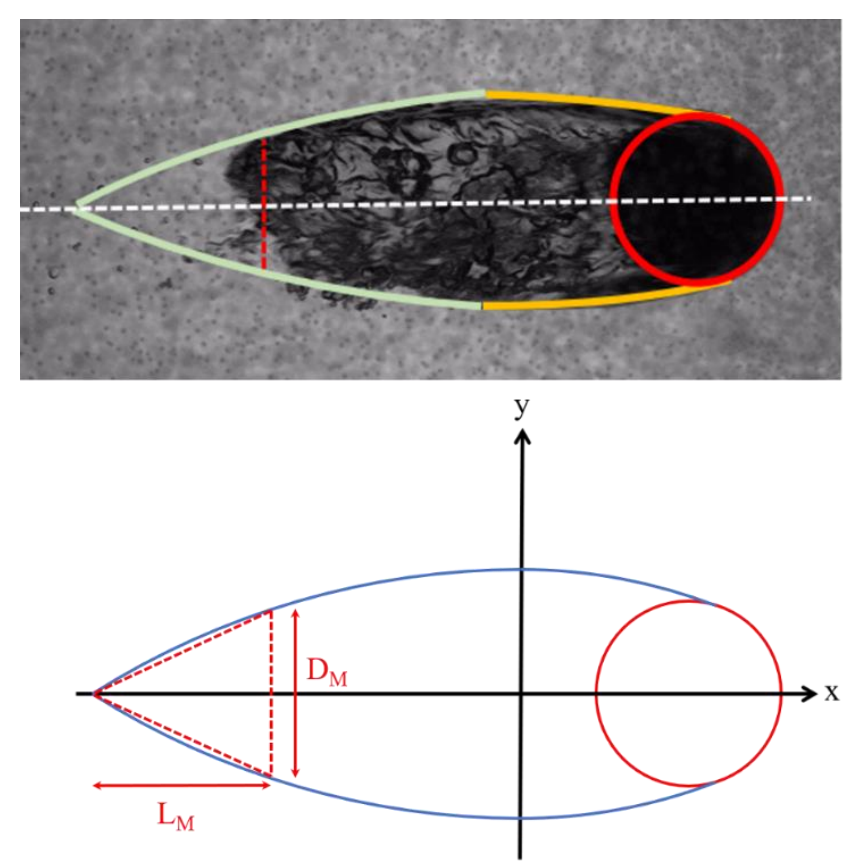

Figure S17 Illustration of curve fitting method of a none-fully developed cavity sustained on a superhydrophobic sphere.

For the non-fully developed cavity, the outline of the cavity was firstly fitted to an intact waterdrop shape. Then the intact volume of the cavity can be calculated using the above method. The cross-section diameter of the rear part of cavity $\mathrm{D}_{\mathrm{M}}$ and length from the tail of fitted water drop to the rear part of cavity $\mathrm{L}_{\mathrm{M}}$ can be measured. The volume of non-fully developed cavity $\mathrm{V}$ ' capture can be calculated by subtracting the volume of 
the missing section of the cavity from the calculated intact volume, as illustrated in Figure S17.

The $L_{M}$ and $D_{M}$ was defined as the length and diameter of the missing section of the cavity. To simplify the calculation, the missing section of the cavity was approximated by the cone, thus, the missing volume can be calculated by $V_{\text {Missing }}=$ $\frac{1}{3} L_{M} \pi D_{M}^{2}$. The volume of the non-fully developed cavity and sphere can be calculated as:

$V_{c}^{\prime}=V_{c}-V_{\text {Missing }}=V_{C}-\frac{1}{3} L_{M} \pi D_{M}^{2}$

The fitted characteristic parameters and calculated volume of the cavity on the spheres with different diameters and releasing heights were shown in Tables S1 to S4.

Table S1 The fitted characteristic parameters and calculated volume of the cavity on the spheres with diameters of $5.0 \mathrm{~mm}$ at different releasing height

\begin{tabular}{ccccccc}
\hline & $\mathrm{L}_{\mathrm{T}} / \mathrm{mm}$ & $\mathrm{L}_{\mathrm{M}} / \mathrm{mm}$ & $\mathrm{D}_{\mathrm{C}} / \mathrm{mm}$ & $\mathrm{D}_{\mathrm{M}} / \mathrm{mm}$ & $\mathrm{L}_{\mathrm{M}} / \mathrm{mm}$ & $\mathrm{V}_{\mathrm{C}} / \mathrm{cm}^{3}$ \\
\hline $10 \mathrm{~cm}$ & $21.5 \pm 0.8$ & $5.4 \pm 0.2$ & 6.2 & $1.0 \pm 0.2$ & $4.6 \pm 1.1$ & 0.4 \\
\hline $20 \mathrm{~cm}$ & $24.3 \pm 0.4$ & $5.2 \pm 0.1$ & 6.2 & & 0.4 \\
\hline $30 \mathrm{~cm}$ & $24.7 \pm 0.3$ & $5.4 \pm 0.2$ & 6.1 & & 0.4 \\
\hline $40 \mathrm{~cm}$ & $24.5 \pm 0.5$ & $5.2 \pm 0.1$ & 6.3 & & 0.5 \\
\hline
\end{tabular}


Table S2 The fitted characteristic parameters and calculated volume of the cavity on the spheres with diameters of $10.0 \mathrm{~mm}$ at different releasing height

\begin{tabular}{lcccccc}
\hline & $\mathrm{L}_{\mathrm{T}} / \mathrm{mm}$ & $\mathrm{L}_{\mathrm{M}} / \mathrm{mm}$ & $\mathrm{D}_{\mathrm{C}} / \mathrm{mm}$ & $\mathrm{D}_{\mathrm{M}} / \mathrm{mm}$ & $\mathrm{L}_{\mathrm{M}} / \mathrm{mm}$ & $\mathrm{V}_{\mathrm{C}} / \mathrm{cm}^{3}$ \\
\hline $10 \mathrm{~cm}$ & $38.1 \pm 3.3$ & $9.0 \pm 6.6$ & $13.0 \pm 0.1$ & $6.1 \pm 0.5$ & $13.5 \pm 1.7$ & $2.8 \pm 0.3$ \\
\hline $20 \mathrm{~cm}$ & $45.3 \pm 2.5$ & $8.0 \pm 5.9$ & $12.9 \pm 0.2$ & $3.8 \pm 0.5$ & $6.5 \pm 2.1$ & $3.7 \pm 0.2$ \\
\hline $30 \mathrm{~cm}$ & $47.8 \pm 1.2$ & $10.8 \pm 0.5$ & $12.7 \pm 0.1$ & & & $4.0 \pm 0.1$ \\
\hline $40 \mathrm{~cm}$ & $50.4 \pm 1.4$ & $10.7 \pm 0.2$ & $12.7 \pm 0.1$ & & & $4.1 \pm 0.1$
\end{tabular}

Table S3 The fitted characteristic parameters and calculated volume of the cavity on the spheres with diameters of $15.0 \mathrm{~mm}$ at different releasing height

\begin{tabular}{ccccccc}
\hline & $\mathrm{L}_{\mathrm{T}} / \mathrm{mm}$ & $\mathrm{L}_{\mathrm{M}} / \mathrm{mm}$ & $\mathrm{D}_{\mathrm{C}} / \mathrm{mm}$ & $\mathrm{D}_{\mathrm{M}} / \mathrm{mm}$ & $\mathrm{L}_{\mathrm{M}} / \mathrm{mm}$ & $\mathrm{V}_{\mathrm{C}} / \mathrm{cm}^{3}$ \\
\hline $10 \mathrm{~cm}$ & $51.9 \pm 2.6$ & $17.8 \pm 1.2$ & $20.1 \pm 0.9$ & $14.0 \pm 2.5$ & $17.6 \pm 1.5$ & $7.9 \pm 2.7$ \\
\hline $20 \mathrm{~cm}$ & $63.6 \pm 2.7$ & $16.8 \pm 1.8$ & $19.9 \pm 0.1$ & $6.2 \pm 1.4$ & $11.5 \pm 5.9$ & $12.8 \pm 0.5$ \\
\hline $30 \mathrm{~cm}$ & $74.6 \pm 0.5$ & $15.8 \pm 0.4$ & $19.0 \pm 0.1$ & $3.7 \pm 0.7$ & $5.1 \pm 0.4$ & $13.8 \pm 0.3$ \\
\hline $40 \mathrm{~cm}$ & $77.1 \pm 0.7$ & $15.7 \pm 0.1$ & 19.2 & & & 14.4 \\
\hline
\end{tabular}


Table S4 The fitted characteristic parameters and calculated volume of the cavity on the spheres with diameters of $19.0 \mathrm{~mm}$ at different releasing height

\begin{tabular}{ccccccc}
\hline & $\mathrm{L}_{\mathrm{T}} / \mathrm{mm}$ & $\mathrm{L}_{\mathrm{M}} / \mathrm{mm}$ & $\mathrm{D}_{\mathrm{C}} / \mathrm{mm}$ & $\mathrm{D}_{\mathrm{M}} / \mathrm{mm}$ & $\mathrm{L}_{\mathrm{M}} / \mathrm{mm}$ & $\mathrm{V}_{\mathrm{C}} / \mathrm{cm}^{3}$ \\
\hline $10 \mathrm{~cm}$ & $63.6 \pm 4.9$ & $23.4 \pm 2.6$ & $24.3 \pm 0.4$ & $19.0 \pm 4.1$ & $20.1 \pm 1.6$ & $13.8 \pm 2.2$ \\
\hline $20 \mathrm{~cm}$ & $74.2 \pm 3.8$ & $24.1 \pm 0.2$ & 24.0 & $13.4 \pm 1.5$ & $15.1 \pm 0.7$ & $20.8 \pm 0.3$ \\
\hline $30 \mathrm{~cm}$ & $88.7 \pm 2.0$ & $22.4 \pm 0.7$ & $24.2 \pm 0.3$ & $3.4 \pm 0.7$ & $6.1 \pm 1.1$ & $27.2 \pm 0.8$ \\
\hline $40 \mathrm{~cm}$ & $96.1 \pm 1.2$ & $21.3 \pm 0.4$ & 24.2 & & & $29.0 \pm 0.4$
\end{tabular}

S9 The calculated $C_{D}$ of the spheres with different wettability, diameters, and releasing height.

Table S5 The calculated $C_{D}$ of the $5.0 \mathrm{~mm}$ spheres with different wettability and releasing height.

\begin{tabular}{ccccc}
\hline $\begin{array}{c}\text { Releasing } \\
\text { height }\end{array}$ & Superhydrophilic & Hydrophilic & Hydrophobic & Superhydrophobic \\
\hline $0 \mathrm{~cm}$ & $0.495 \pm 0.004$ & $0.498 \pm 0.013$ & $0.490 \pm 0.011$ & $0.514 \pm 0.004$ \\
\hline $10 \mathrm{~cm}$ & $0.485 \pm 0.005$ & $0.472 \pm 0.007$ & $0.474 \pm 0.006$ & $0.098 \pm 0.011$ \\
\hline $20 \mathrm{~cm}$ & $0.495 \pm 0.007$ & $0.496 \pm 0.009$ & $0.482 \pm 0.008$ & $0.059 \pm 0.003$ \\
\hline $30 \mathrm{~cm}$ & $0.467 \pm 0.005$ & $0.482 \pm 0.007$ & $0.479 \pm 0.006$ & $0.059 \pm 0.005$ \\
\hline $40 \mathrm{~cm}$ & $0.492 \pm 0.009$ & $0.477 \pm 0.008$ & $0.476 \pm 0.009$ & $0.045 \pm 0.005$ \\
\hline
\end{tabular}


Table S6 The calculated $C_{D}$ of the $10.0 \mathrm{~mm}$ spheres with different wettability and releasing height.

\begin{tabular}{ccccc}
\hline $\begin{array}{c}\text { Releasing } \\
\text { height }\end{array}$ & Superhydrophilic & Hydrophilic & Hydrophobic & Superhydrophobic \\
\hline $0 \mathrm{~cm}$ & $0.486 \pm 0.013$ & $0.478 \pm 0.004$ & $0.479 \pm 0.008$ & $0.486 \pm 0.014$ \\
\hline $10 \mathrm{~cm}$ & $0.493 \pm 0.006$ & $0.464 \pm 0.006$ & $0.489 \pm 0.010$ & $0.182 \pm 0.038$ \\
\hline $20 \mathrm{~cm}$ & $0.476 \pm 0.005$ & $0.486 \pm 0.005$ & $0.472 \pm 0.006$ & $0.081 \pm 0.024$ \\
\hline $30 \mathrm{~cm}$ & $0.482 \pm 0.009$ & $0.479 \pm 0.009$ & $0.480 \pm 0.006$ & $0.050 \pm 0.017$ \\
\hline $40 \mathrm{~cm}$ & $0.476 \pm 0.010$ & $0.483 \pm 0.010$ & $0.465 \pm 0.007$ & $0.036 \pm 0.008$ \\
\hline
\end{tabular}

Table $\mathbf{S} 7$ The calculated $\mathrm{C}_{\mathrm{D}}$ of the $15.0 \mathrm{~mm}$ spheres with different wettability and releasing height.

\begin{tabular}{ccccc}
\hline $\begin{array}{c}\text { Releasing } \\
\text { height }\end{array}$ & Superhydrophilic & Hydrophilic & Hydrophobic & Superhydrophobic \\
\hline $0 \mathrm{~cm}$ & $0.479 \pm 0.004$ & $0.468 \pm 0.002$ & $0.466 \pm 0.008$ & $0.486 \pm 0.007$ \\
\hline $10 \mathrm{~cm}$ & $0.467 \pm 0.003$ & $0.478 \pm 0.004$ & $0.476 \pm 0.014$ & $0.230 \pm 0.080$ \\
\hline $20 \mathrm{~cm}$ & $0.452 \pm 0.006$ & $0.470 \pm 0.006$ & $0.445 \pm 0.012$ & $0.071 \pm 0.017$ \\
\hline $30 \mathrm{~cm}$ & $0.458 \pm 0.009$ & $0.474 \pm 0.009$ & $0.473 \pm 0.014$ & $0.040 \pm 0.009$ \\
\hline $40 \mathrm{~cm}$ & $0.473 \pm 0.016$ & $0.455 \pm 0.016$ & $0.471 \pm 0.017$ & $0.020 \pm 0.001$ \\
\hline
\end{tabular}


Table S8 The calculated $C_{D}$ of the $19.0 \mathrm{~mm}$ spheres with different wettability and releasing height.

\begin{tabular}{ccccc}
\hline $\begin{array}{c}\text { Releasing } \\
\text { height }\end{array}$ & Superhydrophilic & Hydrophilic & Hydrophobic & Superhydrophobic \\
\hline $0 \mathrm{~cm}$ & $0.473 \pm 0.014$ & $0.487 \pm 0.008$ & $0.462 \pm 0.036$ & $0.492 \pm 0.019$ \\
\hline $10 \mathrm{~cm}$ & $0.475 \pm 0.013$ & $0.476 \pm 0.005$ & $0.466 \pm 0.011$ & $0.264 \pm 0.034$ \\
\hline $20 \mathrm{~cm}$ & $0.466 \pm 0.009$ & $0.471 \pm 0.014$ & $0.468 \pm 0.019$ & $0.148 \pm 0.011$ \\
\hline $30 \mathrm{~cm}$ & $0.465 \pm 0.021$ & $0.454 \pm 0.012$ & $0.507 \pm 0.032$ & $0.051 \pm 0.011$ \\
\hline $40 \mathrm{~cm}$ & $0.483 \pm 0.017$ & $0.456 \pm 0.012$ & $0.485 \pm 0.015$ & $0.024 \pm 0.004$ \\
\hline
\end{tabular}

S10 Numerical simulation of the flow field around the spheres with and without the underwater cavity sustained

The numerical simulations were performed with the three-dimensional (3D) Reynolds-averaged Navier-Stokes pressure-based method. The geometric model was built with the software CATIA. Considering that the geometric shapes of the fully developed cavities changed very slightly when the spheres moved uniformly, the wall of the geometric model was set as a solid interface. The typical surface mesh of the geometric model is shown in Figure S18. 


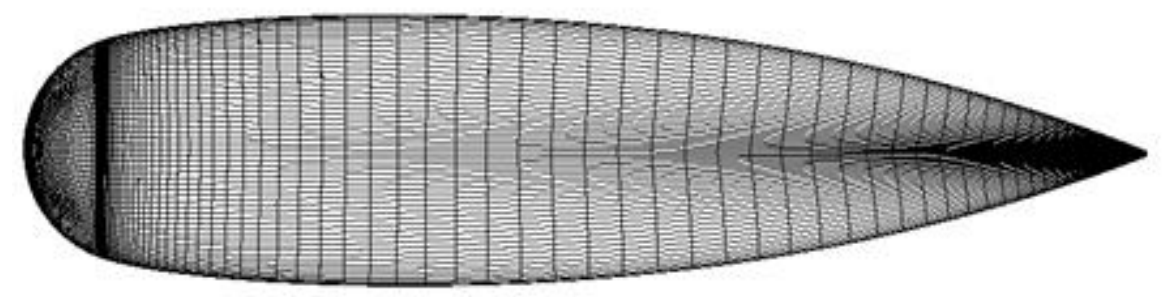

Figure S18 Typical surface mesh of the geometric model

To simulate the flow passed the cavity with free-slip surface, the boundary of the geometric model was divided into two parts: the boundary conditions of solid spherical surface was set non-slip, and the boundary conditions of the constructed cavity surface was free-slip. The velocity inlet boundary of flow, which is equivalent to the falling spheres. The parameters of the hydromechanical model are set as follows: the velocity of the superhydrophobic sphere was set as $1.75 \mathrm{~m} / \mathrm{s}$. The diameter of the sphere was set as $12.7 \mathrm{~mm}$, and the length and maximal diameter was set as 68.7 and $15.16 \mathrm{~mm}$, respectively. The size of the calculated domine was $100 \mathrm{~mm} \times 60 \mathrm{~mm} \times 600 \mathrm{~mm}$, and the boundary conditions of the domine wall was set as slip-free. The pressure outlet boundary was adopted to the bottom of the water channel. The computational Re number domain was as the same as the experimental region. Based on experimental condition, all reference parameters are determined, such as gravity, area, density, length, temperature, velocity, a ratio of specific heats. According to the principle of relative motion, the operating pressure was determined when the effect of gravity was set to $116000 \mathrm{~Pa}$, whose corresponding depth of water was $1.5 \mathrm{~m}$. The number of iterations was less than 1000 in all numerical simulations. 
The parameters of the flow past the bare sphere were set as follows: the velocity of the superhydrophobic sphere was set as $1.58 \mathrm{~m} / \mathrm{s}$. Other diameters were set as same as the case with cavity attached.

The computational case had good converged.

\section{S11 Mechanism of flow separation of the bluff body (sphere)}
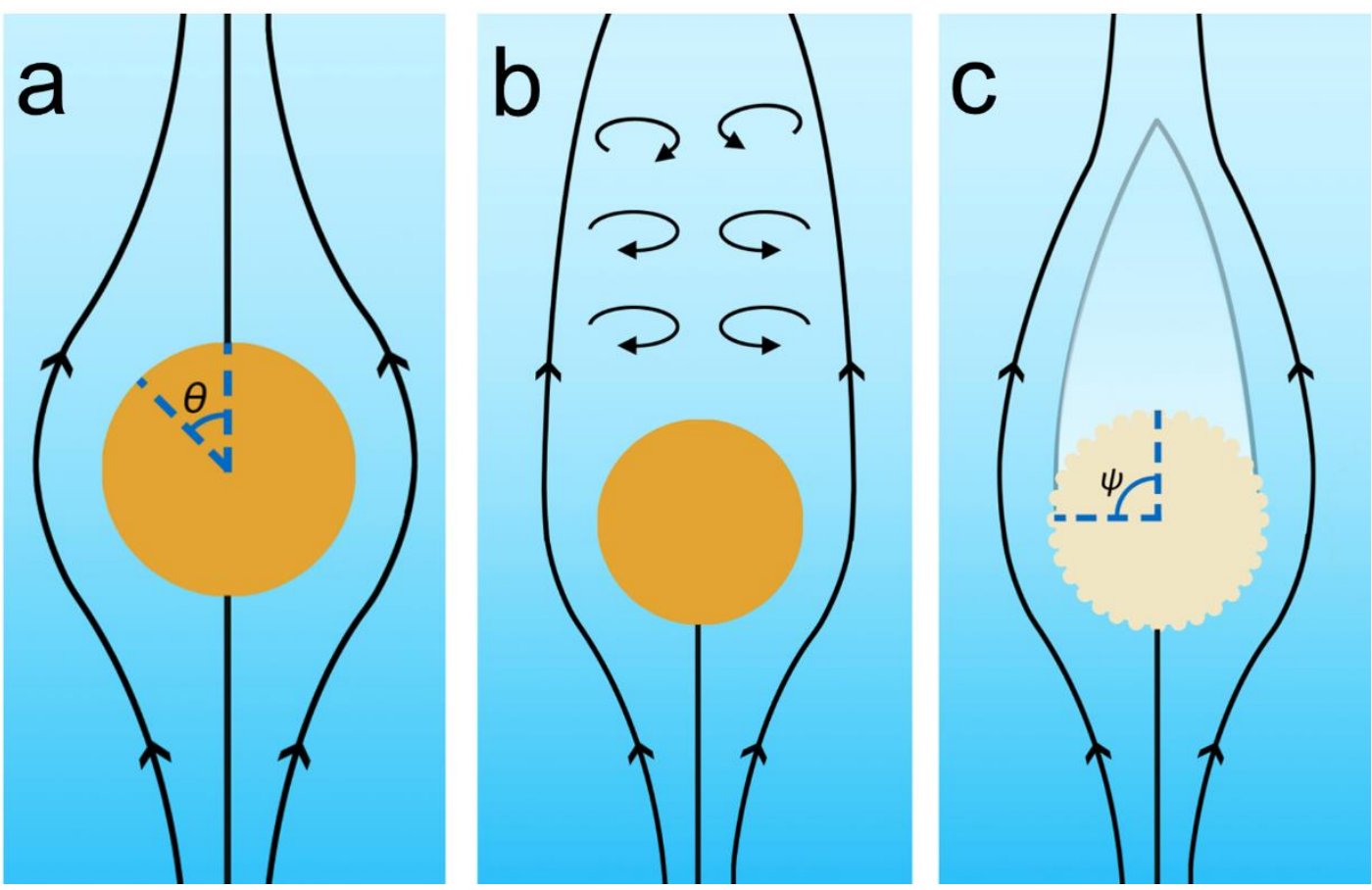

Figure S19 Illustration of the ideal inviscid flow past a sphere (a), actual viscid flow past a sphere, causing a flow separation behind the sphere (b), and actual viscid flow past a sphere with attached cavity, the flow separation was suppressed (c).

In fluid mechanics, the ideal inviscid flow is governed by the Euler equation: 


$$
\rho g-\nabla p=\rho\left[\frac{\partial \overrightarrow{\mathrm{V}}}{\partial \mathrm{t}}+(\overrightarrow{\mathrm{V}} \cdot \nabla) \overrightarrow{\mathrm{V}}\right]
$$

According to equation (1), when the uniform ideal inviscid flow passes a static sphere, the distribution of the pressure on the spherical surface can be described as

$P=P_{\infty}+\frac{1}{2} \rho v^{2}-\frac{9}{8} \rho v^{2}(\sin \theta)^{2}$

where $\mathrm{v}$ is the velocity of the uniform flow, $\theta$ is the radian illustrated in Figure S5a, and $\mathrm{P}_{\infty}$ is the reference pressure. According to equation (2), the pressure distribution is symmetric for the former and rear parts of the sphere, and there is no pressure-induced drag. No skin frictional force was assumed considering that the flow is inviscid. Amazingly, no drag force of the moving sphere is assumed in the flow direction. However, as for the actual fluid, the hydrodynamic drag of the moving sphere is of vital importance and cannot be ignored. This question is the famous D'Alembert's paradox. ${ }^{4}$ The actual viscid flow is governed by the Navier Stokes (NS) equation ${ }^{5}$ :

$\rho g-\nabla p+\mu \nabla^{2} \vec{V}=\rho\left[\frac{\partial \vec{V}}{\partial t}+(\vec{V} \cdot \nabla) \vec{V}\right]$

As compared to the Euler equation (1), the NS equation considers the viscous term $\mu \nabla^{2} \vec{V}$, which makes the NS equation more complex. When the uniform viscid flow passes a static sphere, there was no analytical solution to the NS equation. Experiments have shown that the mainstream separated from the spherical surface around the equator, i.e., flow separation. ${ }^{6}$ There are two causes of the flow separation. The first cause is the adverse pressure gradient near the surface. According to the equation (2), 
when $\theta<90^{\circ}$, the surface pressure increases with the decrease of $\theta$, forming an adverse pressure gradient near the surface. The adverse pressure gradient can slow and block the mainstream. The second cause is the viscosity of the fluid, which will further slow the motion of the mainstream. The mainstream will separate from the spherical surface when the velocity of the mainstream slows to $0 \mathrm{~m} / \mathrm{s}$. After separation, a separated vortex area is formed behind the sphere, as shown in Figure S5b, causing the pressure-induced drag. As for the cavity attached sphere with a streamlined shape, the adverse pressure gradient is significantly reduced by reducing the curvature of the rear part. As a result, the flow separation is suppressed by the streamline body.

\section{S12 The mechanism of drag reduction of the underwater gas-liquid interface}
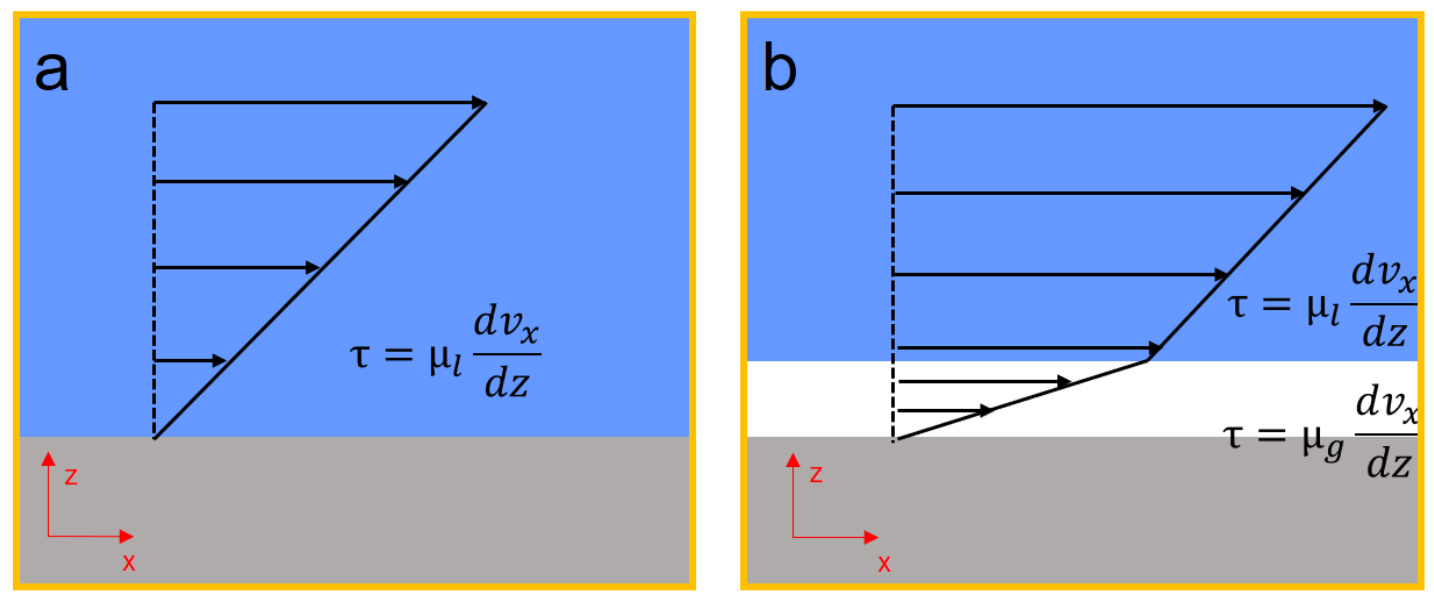

Figure S20 Illustration of the flow boundary at the (a) liquid-solid interface and (b) liquid-gas-solid interface. 
When a viscid Newtonian flow passes over a solid surface, the flow interacts with the solid body through a boundary layer, ${ }^{7}$ as shown in Figure S6a. The boundary layer is defined as a thin film flow near the solid boundary whose linear velocity profile $\frac{d v_{x}}{d z}$ vanished at the solid boundary. The boundary layer connected the shear stress $\tau$ with the shear velocity $v_{x}$ through Newton's law of viscosity: $\tau=\mu_{1} \frac{d v_{x}}{d z}$, where $\mu_{1}$ is the viscosity of liquid. For water, the viscosity is about $10^{-3} \mathrm{~Pa}$. However, the viscosity of the gas is about $10^{-5} \mathrm{~Pa} \mathrm{~s}$, which is two orders of magnitude less than water. As a result, introducing a gas lubricating film can increase the shear velocity of the flow at the same distance from the solid boundary, as shown in Figure S6b. On the other hand, the gas lubricating film can reduce the shear force, i.e. the skin friction, under the same external flow velocity.

\section{S13 The sphericity of the spheres}

To investigate the sphericity of the spheres used in our experiment, we measured the three-dimensional topography of the spheres with three-dimensional profilometer (InfiniteFocus G5, Alicona, Austria). The three-dimensional contour maps of the top surface of the spheres were measured using the Image Field mode, and then the Gaussian fitting was used to calculate the sphericity of the sphere. Three-dimensional contour maps of the spheres with different diameter $(5.0 \mathrm{~mm}, 10.0 \mathrm{~mm}, 15.0 \mathrm{~mm}$, and $19.0 \mathrm{~mm}$ ) were shown in Figure S21. The diameters of the spheres calculated using the Gaussian fitting method were illustrated in Table S9. 
(a)

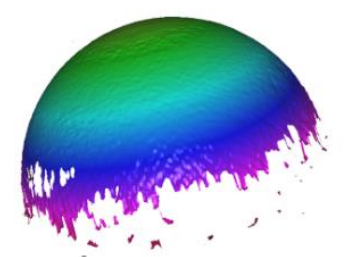

(c)

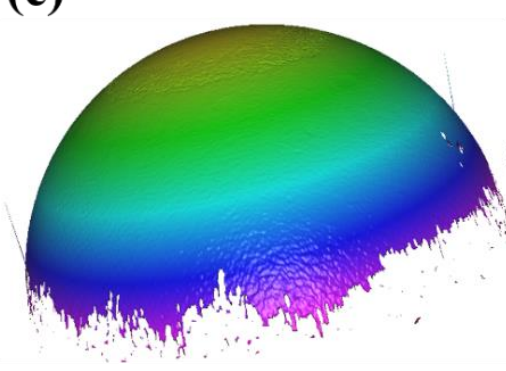

(b)
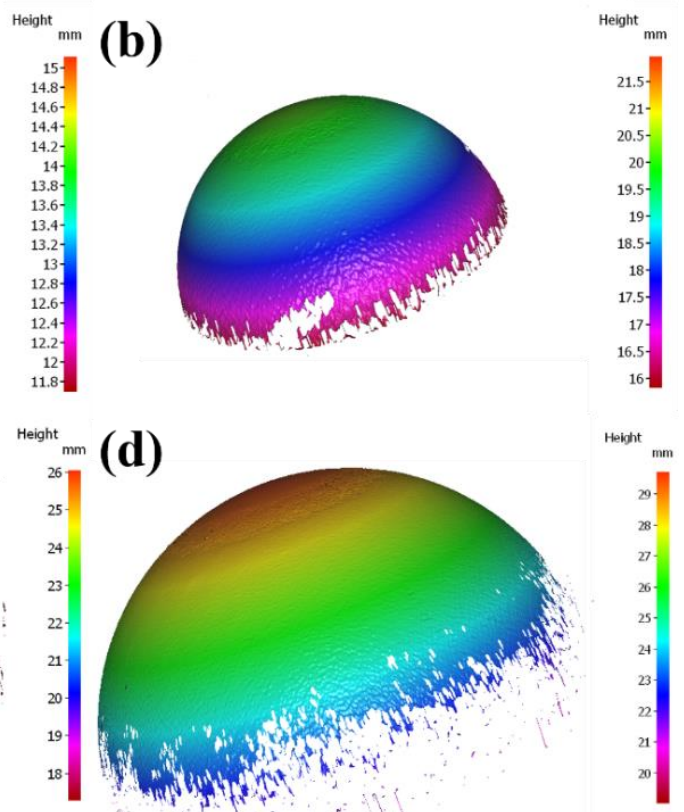

(d)

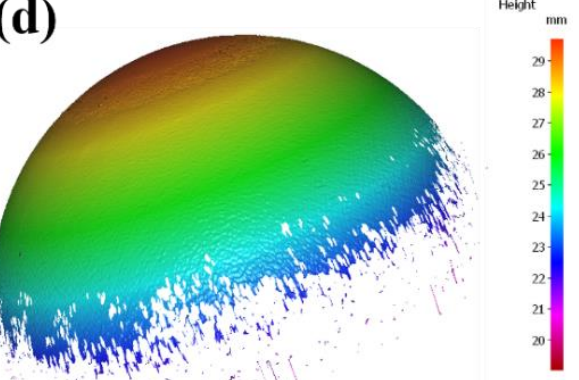

Figure S21: The three-dimensional contour maps of the spheres with intrinsic diameter of $5.0 \mathrm{~mm}$ (a), $10.0 \mathrm{~mm}(\mathrm{~b}), 15.0 \mathrm{~mm}(\mathrm{c})$, and $19.0 \mathrm{~mm}$ (d).

Table S9: The calculated diameters of the spheres using the Gaussian fitting method.

\begin{tabular}{llll}
\hline Intrinsic diameter & $\begin{array}{l}\text { Calculated } \\
\text { diameter } / \mathrm{mm}\end{array}$ & $\begin{array}{l}\text { Mean deviation } \\
/ \mu \mathrm{m}\end{array}$ & $\begin{array}{l}\text { Number of fitting } \\
\text { points }\end{array}$ \\
\hline 5.0 & 5.000 & 3.618 & 1538861 \\
\hline 10.0 & 10.030 & 5.417 & 6300100 \\
\hline 15.0 & 14.982 & 4.867 & 6300100 \\
\hline 19.0 & 19.052 & 8.919 & 2530877 \\
\hline
\end{tabular}


The calculated diameters by Gaussian fitting method were very closed to the intrinsic diameters of spheres with small mean deviations. These results indicate that our spheres used in the experiment had a good sphericity.

Movie 1. The water entry process of a superhydrophobic sphere with a diameter of the $10.0 \mathrm{~mm}$ at a releasing height of $30.0 \mathrm{~cm}$

Movie 2. The water entry process of a hydrophobic sphere with a diameter of the 10.0 $\mathrm{mm}$ at a releasing height of $30.0 \mathrm{~cm}$

Movie 3. The underwater motion behavior of a superhydrophobic sphere with a diameter of the $10.0 \mathrm{~mm}$ at a releasing height of $30.0 \mathrm{~cm}$

\section{Reference}

1. Chen, H., Liu, H., Gao, P., \& Ding, H. (2020). Submersion of impacting spheres at low Bond and Weber numbers owing to a confined pool. Journal of Fluid Mechanics, 884, A 13

2. Fidleris, V., \& Whitmore, R. L. (1961). Experimental determination of the wall effect for spheres falling axially in cylindrical vessels. British Journal of Applied Physics, 12(9), 490-494.

3. Vakarelski, I. U.; Klaseboer, E.; Jetly, A.; Mansoor, M. M.; Aguirrepablo, A. A.; Chan, D.; Thoroddsen, S. T. Self-determined Shapes and Velocities of Giant Nearzero Drag Gas Cavities. Sci. Adv. 2017, 3, e1701558. 
4. R. L. Daugherty, A. C. Ingersoll, Fluid mechanics, McGraw-Hill, 1954.

5. L. D. Landau, J. B. Sykes, W. H. Reid, Fluid mechanics, Pergamon Press, 1959.

6. E. Achenbach, Journal of Fluid Mechanics 1972, 54, 565.

7. C. Cottin-Bizonne, J. L. Barrat, L. Bocquet, E. Charlaix, Nature materials 2003, 2, 237. 